
$\mathrm{SCIDOC}$
International Journal of Respiratory Disease, Care \& Medicine (IJRDM) ISSN: $2577-4409$

\title{
The Effect of Salmeterol, Tiotropium Bromide and its Combination in Patients with Acute Exacerbation Of Chronic Obstructive Pulmonary Disease
}

Omid Otroshi ${ }^{1}$, Mohammad Ali Saba $^{1 *}$, Abdulhossein DavodAbadi ${ }^{1}$, Azam Zilochian ${ }^{1}$

Autoimmune Diseases Research Center, Kashan University Of Medical Sciences, Kashan, Iran.

\section{Abstract}

Background: In order to managing patients with acute exacerbated COPD, long-acting anticholinergic drugs and long-acting beta-agonists are used alone. Therefore, the purpose of this study was to investigate the effect of salmeterol, tiotropium bromide and its combination in patients with acute exacerbation of chronic obstructive pulmonary disease.

Materials and Methods: This tripartite clinical trial study was performed on patients with acute exacerbated COPD referred to the Emergency Department of Shahid Beheshti Hospital of Kashan in 2019 (135 people). Patients were randomly divided into three groups. For each of the three groups, salmeterol sprays, tiotropium bromide and combination were administered separately during the admission. FEV1 and FVC measures were evaluated before and after the intervention for all three groups via spirometry. Data were analyzed using chi-square test, ANOVA, paired t-test and covariance analysis.

Results: The results of covariance analysis (age variables and pre-intervention as covet) indicated a significant difference between the three groups of salmeterol (60/137), tiova (98/98) and combination 0f both medications(167.64) in terms of FEV1 variable $(\mathrm{P}<0.001)$ and between the three groups of salmeterol (146.41), tiova (12.51) and combination (29.22) in terms of FVC variable $(\mathrm{p}<0.001)$.

Conclusion: The findings of this study confirm the significant impact of combination of two long-acting bronchodilators with different pharmacological mechanisms in patients who need two drug classes for control of their disease is effective for them.

Keywords: Acute Exacerbated COPD; Salmeterol; Tiotropium Bromide; FEV1; FVC.

\section{Introduction}

Acute exacerbation of chronic pulmonary obstructive pulmonary disease (AECOPD) is a condition that is characterized by progressive airway obstruction in the lungs [1]. AECOPD is a disease that is diagnosed with three symptoms of coughing, phlegm, and shortness of breath [2]. The World Health Organization (WHO) estimates in 2008 that 210 million people in the world are suffering from COPD and that the overall COPD mortality rate will increase by more than $30 \%$ over the next 10 years [3].

COPD is the fourth leading cause of death in the world, affecting $10 \%$ of adults over 40 years of age [4]. According to a study in Tehran, in people aged 18 years and older, the incidence of COPD was $9.2 \%$ in 2015 [5]. AECOPD is usually associated with reduced lung function. These patients experience symptoms such as cough with sputum, reduced exercise tolerance, wheezing, shortness of breath and prolonged exhalation [6]. Patients usually complain of decreased activity levels due to shortness of breath or fatigue, or both of them. These symptoms affect the daily activity of patients [7]. Cough is also an important symptom in these patients, as it causes discomfort and poor quality of life [8]. Therefore, in order to control symptoms, improve the health status and reduce the incidence of COPD, the necessity for care and treatment in these patients is highly necessary [9]. Tiotropium bromide is a long-acting inhaled drug that helps to dilate airways and is used to manage AECOPD. Based on the evidence from the trials, continuous therapy with tiotropium bromide has significantly reduced AECOPD and hospitalization risk due to exacerbation of the disease [11,12]. Another inhaled bronchodi-

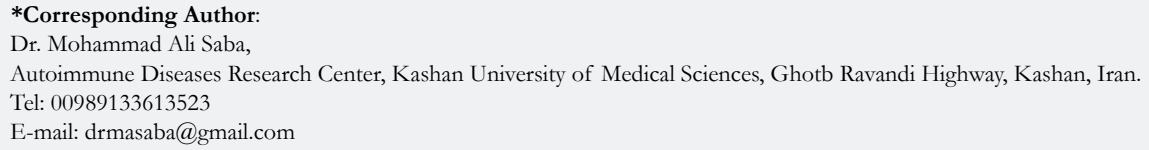

Citation: Omid Otroshi, Mohammad Ali Saba, Abdulhossein DavodAbadi, Azam Zilochian. The Effect of Salmeterol, Tiotropium Bromide and its Combination in Patients with Acute Exacerbation Of Chronic Obstructive Pulmonary Disease. Int J Resp Dis Care Med. 2020;4(1):54-58. doi: http://dx.doi.org/10.19070/2577-4409-2000010

Copyright: Mohammad Ali Saba 2020. This is an open-access article distributed under the terms of the Creative Commons Attribution License, which permits unrestricted use, distribution and reproduction in any medium, provided the original author and source are credited. 
lator drug used in patients with COPD is salmeterol. Salmeterol is one of the direct-acting sympathetic mimic drugs that stimulates beta-adrenoceptor activity and optionally selects beta- 2 receptors (a beta 2 agonist) [13]. In addition to bronchodilator properties, it has anti-inflammatory activity [14] and decreased bio sorbent reactivity and mucosal clarity [15]. Several controlled trials have reported the efficacy and safety of these drug agents (tiotropium bromide and salmeterol) as a single treatment in COPD [16-19].

Several clinical trials have been conducted on the combination of anticholinergics and adrenergic agonist drugs as a long-term bronchodilator, and the potential benefits of administering daily tiotropium bromide with adrenoceptor agonists twice daily have been reported to improve lung function and clinical positive outcomes [20-22]. In general, considering the single efficacy of tiotropium bromide inhaler capsules and salmeterol spray in COPD, and regarding that most studies conducted evaluating the combination of tiotropium bromide with Formoterol. Therefore, the aim of this study was to investigate the effect of salmeterol, tiotropium bromide and their combination in patients with acute exacerbated COPD.

\section{Methods}

\section{Study Type and Participants}

This study was a single-blind randomized clinical trial in 3 groups. This study was conducted from April to March 2013 on 135 patients with acute exacerbated COPD referred to the Emergency Department of Shahid Beheshti Hospital in Kashan, Iran. In order to estimate the sample size, according to the previous study [23], with $95 \%$ confidence and statistical power of $90 \%$, the minimum required sample size was calculated for 38 persons in each group, and with $20 \%$ drop, 45 persons were considered for each group.

Inclusion criteria include: Individuals willing to participate in the study, Adults over the age of 45 years with AECOPD due to the severity of symptoms defined on the basis of the GOLD criteria (cough, sputum production, dyspnea, or history of exposure to risk factors) present to the hospital, Patients reporting a history of at least 10 cigarette pocket a day, patients with documented medical records that shows had an airway obstruction (FEV1/ FVC ratio less than 0.7 and FEV1 after treatment bronchodilator less than 0.65), and Patients diagnosed with COPD by spirometry.

Non-inclusion criteria include: patients with allergic rhinitis, atopy, positive skin test, patients with eosinophil count of more than $400 \mathrm{~mm}$, patients with other pulmonary disorders or cardiopulmonary disorders, patients with recent history of myocardial infarction, previous failure, or arrhythmia required medication, prostatic hypertrophy and glaucoma with closed angle [24]. Exclusion criteria included: patient's decision to withdraw, use of other bronchodilator drugs other than salmeterol spray or tiotropium bromide (thiourea) capsule during the study, irregular use of salmeterol spray and tiotropium capsule in terms of the amount and time of use and death of the patient.

\section{Sampling}

Patients entered the study if they had the criteria for entering and providing comprehensive explanations by the researcher if they were satisfied and completed a written informed consent form. After selecting patients in a continuous manner, using a randomized computer table, through a triple and six-member blocking with a 1:1: 1 assignment ratio, divided into three groups of 45 (salmeterol spray receptor group, capsule recipient group Inhaled tiotropium bromide and the combination salmeterol and tiotropium bromide spray group). Patients are voluntarily and free of charge and can be removed at any stage of the study without any restrictions.

\section{Study plan}

For each of the three groups, salmeterol sprays, tiotropium bromide and combination were administered separately during the admission. Salmeterol spray, which was manufactured by Sina Drug, was given three times a day at a dose of 25 micrograms. Tiotropium Bromide Capsules Imported by Shafiabat Gostar Pharmaceuticals using oral Handihaler was given as an inhaler twice daily with a dose of $18 \mu \mathrm{g}$. The combined use of salmeterol spray and tiotropium bromide capsules by simultaneous administration of salmeterol spray with 25 micrograms twice daily and tiotropium bromide, 18 micrograms once daily. Spray and inhalation capsules were used by the nurses who were selected as research fellow. Patients during the study period were evaluated by a researcher and expert in the lung and were evaluated clinically as the patient was clinically free of symptoms.

Ethical considerations: This study was conducted according to guidelines published in the Helsinki Statement. To conduct this study, the Ethics Committee of Kashan University of Medical Sciences was licensed (IR.KAUMS.MEDNT.REC.1397.32) and the study was registered on the website of the Iranian Clinical Trials (IRCTID: IRCT20190123042466N1).

\section{Data gathering tools}

At the beginning of the study, after completing the personal information questionnaire by self-report and with the help of the researcher, FEV1 and FVC by Spirometry (Elite DL, MedGraphicss, St Paul, MN, USA) Immediately before receiving Spray or Inhaler capsules and then 0,30 minutes, 1, 2, 4, 6, 8, 10, 12, 14, 16, 18, 20, 22 and 24 hours after medication AUCs FVE1 and AUCs FVC through the trapezoidal rule Calculated.

Considering the fact that this study was performed on patients with AECOPD and according to the hemodynamic condition of the patients, 5 patients from each group were excluded from the study because of their unwillingness to continue co-operation and concurrent use of other bronchodilator drugs, so the analysis Data analysis was performed on 120 patients.

\section{Statistical analysis}

The Kolmogorov-Smirnov test was used to verify normality and confirmed. Using descriptive and inferential statistics such as Chisquare and one-way ANOVA (to compare the status of demographic variables in the three study groups), paired t-test was used to evaluate the mean FEV1 AUCs and FVC AUCs 2 times before and after the intervention in three The covariance test was used to remove the confounding factors and Bonferron's post hoc test to compare two drugs. Data were analyzed by SPSS software (Ver- 
sion 16.0, Chicago, USA). In all cases, the significance level was considered to be 0.05 .

\section{Findings}

In this study, 120 people entered the final analysis stage (Figure 2). There was no significant difference between the two groups in terms of demographic characteristics. However, there was a significant difference in age $(\mathrm{P}=0.02)$ between the three groups (Table 1). The results of covariance analysis (age, FVC, and FEV1 variables before intervention as covet) indicated a significant difference between the three groups of salmeterol (60.137), tiova (98/98) and combination (167.64) in terms of FEV1 variable AUCs, as well as between the three groups of salmeterol $(144 / 40)$, tiova $(12 / 50)$ and combination $(292,230)$ in terms of variables AUCs FVC ( $<<0.001)$ (Figures 1 and 2). Before and after intervention, the FEV1 AUCs and FVC AUCs were observed in each of the three groups $(p<0.001)$ (Table 2). Following the significant difference between the three groups, a follow-up test was used to examine the pair of meanings, the results of which are presented in Table 3 .

\section{Discussion}

The aim of this study was to investigate the effect of salmeterol, tiotropium bromide and their combination in patients with acute exacerbation of chronic obstructive pulmonary disease. The findings of the study showed that the average of the AUCs of FEV1 and AUCs of FVC in the combined group of both groups and in the salmeterol group was significantly higher than the tiotropium bromide group. Together with this finding, Oba et al., (2018) found that the combination of long-acting muscarinic antagonist (LAMA) and long-acting beta-agonist (LABA) with the highest therapeutic effect has been exacerbated by COPD reduction [25].

Noord et al., (2010) also in another study found that, 24 hours af-

Figure 1. The mean FVC changes before administration of spray and capsule in each intervention group up to 24 hours after administration.

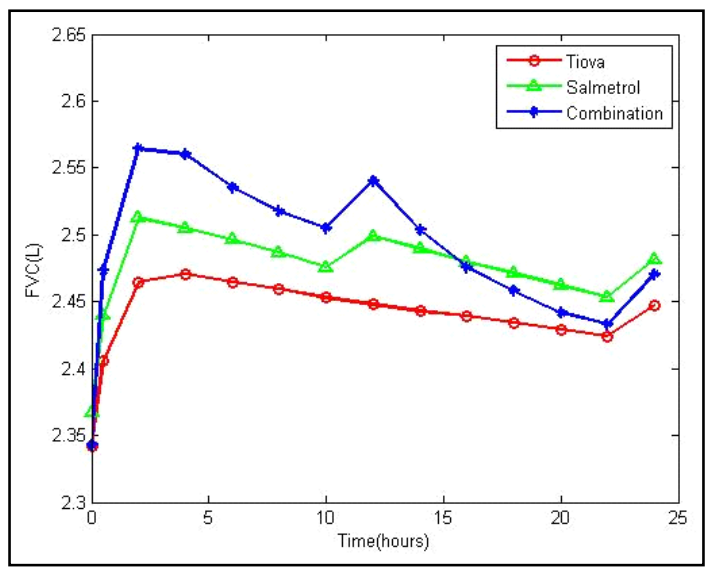

Figure 2. Mean changes of FEV1 before administration of spray and capsule in each intervention group up to 24 hours after administration.

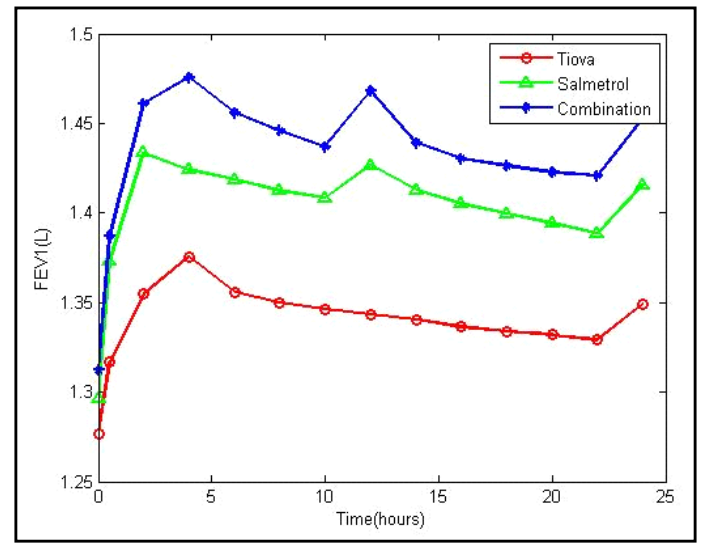

Table 1. Dempgraphic characteristics between the three groups of salmeterol, tiova and combination.

\begin{tabular}{|c|c|c|c|c|c|}
\hline \multicolumn{2}{|c|}{ Groups Variable } & Salmeterol & Tiova & Combination & p-value \\
\hline \multicolumn{2}{|c|}{ Age (mean \pm standard deviation) } & $65.97 \pm 7.73$ & $67.72 \pm 6.73$ & $70.72 \pm 8.27$ & $* 0.020$ \\
\hline \multirow{2}{*}{ Sex $(\mathrm{N}(\%)$} & Male & $39(97.5)$ & $38(95)$ & $38(95)$ & \multirow{2}{*}{$* * 0.812$} \\
\cline { 2 - 5 } & Female & $1(2.5)$ & $2(5)$ & $2(5)$ & \\
\hline \multicolumn{2}{|c|}{ Cigarette pack (mean \pm standard deviation) } & $40 \pm 13.18$ & $37.50 \pm 13.34$ & $39.37 \pm 18.04$ & $* 0.740$ \\
\hline
\end{tabular}


Table 2. Analysis of covariance for comparison of mean FEV1 scores between the three groups of salmeterol, tiova and combination Adjusted based on age variables and before intervention.

\begin{tabular}{|c|c|c|c|c|c|c|c|c|}
\hline \multirow{2}{*}{\multicolumn{2}{|c|}{$\begin{array}{c}\text { Group } \\
\text { Variable }\end{array}$}} & \multicolumn{2}{|c|}{ Salmeterol } & \multicolumn{2}{|c|}{ Tiova } & \multicolumn{2}{|c|}{ Combination } & \multirow{2}{*}{$*_{\mathrm{p} \text {-value }}$} \\
\hline & & $\mathrm{M} \pm \mathrm{SD}$ & $\begin{array}{l}\text { \Adjusted } \\
\text { mean }\end{array}$ & $\mathrm{M} \pm \mathrm{SD}$ & $\begin{array}{l}\text { \$Adjusted } \\
\text { mean }\end{array}$ & $\mathrm{M} \pm \mathrm{SD}$ & $\begin{array}{l}\text { \Adjusted } \\
\text { mean }\end{array}$ & \\
\hline FEV1 & Before & $41.00(7.08)$ & \multirow{2}{*}{137.6} & $40.22(7.38)$ & \multirow{2}{*}{98.98} & $38.97(8.21)$ & \multirow{2}{*}{167.64} & \multirow[t]{2}{*}{0.001} \\
\hline & After & $137.27(6.42)$ & & $98.92(9.75)$ & & $168.02(13.34)$ & & \\
\hline & ${ }^{* *}$ p-value & 0.001 & & 0.001 & & 0.001 & & \\
\hline \multirow[t]{3}{*}{ FVC } & Before & 76.04(8.31) & 146.4 & 72.12(7.16) & 126.5 & 69.17(13.86) & 229.3 & \multirow{2}{*}{0.001} \\
\hline & After & $145.54(6.54)$ & & $126.32(14.86)$ & & $230.45(26.30)$ & & \\
\hline & ${ }^{* *} \mathrm{p}$-value & 0.001 & & 0.001 & & 0.001 & & \\
\hline
\end{tabular}

$\int$ Adjusted mean based on the age's variable and before the intervention

Table 3. Bonferroni post hoc test results to examine the difference between the pair of FEV1 and FVC averages.

\begin{tabular}{|c|c|c|c|}
\hline Variable & groups & Mean difference & p-value \\
\hline \multirow{3}{*}{ FEV1 } & Salmeterol - Tiova & 38.61 & 0.001 \\
\cline { 2 - 4 } & Salmeterol - Combination & -30.04 & 0.001 \\
\cline { 2 - 4 } & Tiova - Combination & -68.66 & 0.001 \\
\hline \multirow{3}{*}{ FVC } & Salmeterol - Tiova & 19.92 & 0.001 \\
\cline { 2 - 4 } & Salmeterol - Combination & -82.89 & 0.001 \\
\cline { 2 - 4 } & Tiova - Combination & -102.82 & 0.001 \\
\hline
\end{tabular}

ter treatment, the combined effect of Salmeterol-Tiova on average of FEV1 and FVC was significantly higher than that of the two drugs separately [26]. Pasco et al., (2009) found that, compared to placebo, Tiova with salmeterol and pulmonary rehabilitation were associated with improved pulmonary function (improved FEV1 and FVC) [27]. Aaron et al., (2007) also reported that the combination of Tiova, Salmeterol and Fluticasone significantly improved pulmonary function and quality of life, also reduced the number of hospitalization days associated with exacerbated COPD compared to placebo and Tiova [28].

In confirmation of this finding, Marco et al., (2006) found in their study that a significant improvement of FEV1 and FVC was achieved after 0-12 hours after the combination of Formetroline and Tiova compared to the separate doses of the two drugs [23].

Villar et al. (2005) also found that the use of the Fluticasone -salmeterol-Tiova combination significantly improved the lung function (FEV1) in patients with moderate to severe COPD compared with the combination of Fluticasone -Tiova-placebo and the combination of Fluticasone - Tiova-placebo [29]. Other study findings (2004), additionally revealed that using Formetrol (as a long-acting beta-agonist) in combination with Tiova initiated a fast and maximal bronchodilation effect compared to single use of Tiova [30]. Harrison (2018), cited that prescription of both inhaled beta-agonist and muscarinic antagonist therapy, caused improvement in lung function, so that the effect of combination therapy is more effective than separate doses in reducing exacerbations [31].

Bronchodilation can be achieved by stimulating adrenergic betaagonist receptors or by inhibiting acetylcholine action in muscarinic receptors with anticholinergic agents [32]. Due to the fact that beta-agonists and anticholinergics have different mechanisms of action that can involve different airway locations, and both drugs have long-term binding to the recipients, it provides the possibility of sustained bronchodilation. It is expected to observe additional effects due to potential beta-agonists which directly affect the cholinergic system.

\section{Conclusion}

The findings of this study confirm the significant impact of combination of two long-acting bronchodilators with different pharmacological mechanisms in patients who need two drug classes for control of their disease is effective for them.

\section{Acknowledgement}

This study has been approved by ethical committee of Kashan University of Medical Sciences with the code of IR.KAUMS. REC.1397.085 The authors are grateful to all the patients who participated in the study and the supervisors of Shahid Beheshti hospital.

\section{References}

[1]. Cheyne L, Irvin-Sellers MJ, White J. Tiotropium versus ipratropium bromide for chronic obstructive pulmonary disease. Cochrane Database Syst Rev. 2013; 9. PMID: 24043433.

[2]. Nazir SA, Erbland ML. Chronic obstructive pulmonary disease. Drugs \& aging. 2009; 26(10): 813-31.

[3]. Statistics - COPD Foundation. https://www.copdfoundation.org/What-isCOPD/Understanding HYPERLINK "http://www.copdfoundation.org/ What-is-COPD/Understanding-COPD/Statistics.aspx"-COPD/Statistics. aspx 2017 [cited 47 1]. 207-14.

[4]. Varmaghani M, Farzadfar F, Sharifi F, Rashidian A, Moin M, Moradi-Lakeh 
$\mathrm{M}$, et al. Prevalence of asthma, COPD, and chronic bronchitis in Iran: A systematic review and meta-analysis. Iranian Journal of Allergy, Asthma and Immunology. 2016; 15(2): 93-104. PMID: 27090362.

[5]. Sharifi H, Masjedi MR, Emami H, Ghanei M, Eslaminejad A, Radmand G, et al. Burden of obstructive lung disease study in Tehran: Prevalence and risk factors of chronic obstructive pulmonary disease. Lung India: official organ of Indian Chest Society. 2015; 32(6): 572-577. PMID: 26664162.

[6]. Brunner LS. Brunner \& Suddarth's textbook of medical-surgical nursing: Lippincott Williams \& Wilkins; 2010.

[7]. Meek PM, Lareau SC. Critical outcomes in pulmonary rehabilitation: assessment and evaluation of dyspnea and fatigue. Journal of rehabilitation Research and Development. 2003; 40(5): 13 - 24. PMID: 15074450.

[8]. McGarvey L, Morice A. Clinical cough and its mechanisms. Respiratory physiology \& neurobiology. 2006; 152(3): 363-71. PMID: 16406741.

[9]. O'donnell DE, Hernandez P, Kaplan A, Aaron S, Bourbeau J, Marciniuk $D$, et al. Canadian Thoracic Society recommendations for management of chronic obstructive pulmonary disease- 2008 update-highlights for primary care. Canadian Respiratory Journal. 2008; 15(Suppl A): 1A-8A. PMID: 18292855 .

[10]. Gerald LB, Bailey WC. Global initiative for chronic obstructive lung disease. Journal of Cardiopulmonary Rehabilitation and Prevention. 2002; 22(4): 234-44.

[11]. Farne HA, Cates CJ. Long-acting beta2-agonist in addition to tiotropium versus either tiotropium or long-acting beta2-agonist alone for chronic obstructive pulmonary disease. The Cochrane Library. 2015. PMID: 26490945.

[12]. Barr RG, Bourbeau J, Camargo CA, Ram FS. Tiotropium for stable chronic obstructive pulmonary disease: a meta-analysis. Thorax. 2006; 61(10): 85462. PMID: 16844726

[13]. Chowdhury BA, Dal Pan G. The FDA and safe use of long-acting beta-agonists in the treatment of asthma. New England Journal of Medicine. 2010; 362(13): 1169-71. PMID: 20181964.

[14]. Anderson R, Feldman C, Theron A, Ramafi G, Cole P, Wilson R. Antiinflammatory, membrane-stabilizing interactions of salmeterol with human neutrophils in vitro. British journal of pharmacology. 1996; 117(7): 138794. PMID: 8730730.

[15]. Johnson M, Rennard S. Alternative mechanisms for long-acting $\beta 2$ adrenergic agonists in COPD. Chest. 2001; 120(1): 258-70. PMID: 11451847.

[16]. Dransfield MT, Bailey WC. Maintenance pharmacotherapy of chronic obstructive pulmonary disease: an evidence-based approach. Expert opinion on pharmacotherapy. 2005; 6(1): 13-25. PMID: 15709879.

[17]. Cooper C, Tashkin D. Recent developments in inhaled therapy in stable chronic obstructive pulmonary disease. BMJ: British Medical Journal. 2005; 330(7492): 640-644. PMID: 15774995.

[18]. Chen AM, Bollmeier SG, Finnegan PM. Long-acting bronchodilator therapy for the treatment of chronic obstructive pulmonary disease. Annals of Pharmacotherapy. 2008; 42(12): 1832-42. PMID: 18957624.

[19]. Friedman M, Cioppa GD, Kottakis J. Formoterol therapy for chronic obstructive pulmonary disease: a review of the literature. Pharmacotherapy: The Journal of Human Pharmacology and Drug Therapy. 2002; 22(9): 1129-39. PMID: 12222549.

[20]. Van Noord J, Aumann J, Janssens E, Smeets J, Verhaert J, Disse B, et al. Comparison of tiotropium once daily, formoterol twice daily and both com- bined once daily in patients with COPD. European Respiratory Journal. 2005; 26(2): 214-22. PMID: 16055868.

[21]. Van Noord JA, Aumann JL, Janssens E, Verhaert J, Smeets JJ, Mueller A, et al. Effects of tiotropium with and without formoterol on airflow obstruction and resting hyperinflation in patients with COPD. Chest. 2006; 129(3): 509-17. PMID: 16537846.

[22]. Tashkin DP, Littner M, Andrews CP, Tomlinson L, Rinehart M, DenisMize K. Concomitant treatment with nebulized formoterol and tiotropium in subjects with COPD: a placebo-controlled trial. Respiratory medicine. 2008; 102(4): 479-87. PMID: 18258423.

[23]. Di Marco F, Verga M, Santus P, Morelli N, Cazzola M, Centanni S. Effect of formoterol, tiotropium, and their combination in patients with acute exacerbation of chronic obstructive pulmonary disease: a pilot study. Respiratory medicine. 2006; 100(11): 1925-32. PMID: 16626956.

[24]. Cazzola M, Centanni S, Santus P, Verga M, Mondoni M, Di Marco F, et al. The functional impact of adding salmeterol and tiotropium in patients with stable COPD. Respiratory medicine. 2004; 98(12): 1214-21. PMID: 15588043.

[25]. Oba Y, Keeney E, Ghatehorde N, Dias S. Dual combination therapy versus long-acting bronchodilators alone for chronic obstructive pulmonary disease (COPD): a systematic review and network meta-analysis. Cochrane Database of Systematic Reviews. 2018; 12(12). PMID: 30521694.

[26]. Van Noord J, Aumann J-L, Janssens E, Smeets J, Zaagsma J, Mueller A, et al. Combining tiotropium and salmeterol in COPD: effects on airflow obstruction and symptoms. Respiratory medicine. 2010; 104(7): 995-1004. PMID: 20303247.

[27]. Pasqua F, Biscione G, Crigna G, Auciello L, Cazzola M. Combining triple therapy and pulmonary rehabilitation in patients with advanced COPD: a pilot study. Respiratory medicine. 2010; 104(3): 412-7. PMID: 19892540.

[28]. Aaron SD, Vandemheen KL, Fergusson D, Maltais F, Bourbeau J, Goldstein $\mathrm{R}$, et al. Tiotropium in combination with placebo, salmeterol, or fluticasone-salmeterol for treatment of chronic obstructive pulmonary disease: a randomized trial. Annals of internal medicine. 2007;146(8):545-55. PMID: 17310045.

[29]. Villar AB, Pombo CV. Bronchodilator efficacy of combined salmeterol and tiotropium in patients with chronic obstructive pulmonary disease. Archivos de Bronconeumología. 2005;41(3):130-4. PMID: 15766465.

[30]. Cazzola M, Di Marco F, Santus P, Boveri B, Verga M, Matera MG, et al. The pharmacodynamic effects of single inhaled doses of formoterol, tiotropium and their combination in patients with COPD. Pulmonary pharmacology \& therapeutics. 2004;17(1):35-9. PMID: 14643169.

[31]. Malani PN. Harrison's principles of internal medicine. JAMA. 2018;308(17):1813-4

[32]. Cazzola M, Centanni S, Santus P, Verga M, Mondoni M, Di Marco F, et al. The functional impact of adding salmeterol and tiotropium in patients with stable COPD. Respiratory medicine. 2004; 98(12):1214-21. PMID: 15588043.

[33]. Vestbo J, Agustí A, Anzueto A, Decramer M, Fabbri L, Jones P. Global strategy for the diagnosis, management and prevention of COPD, Global Initiative for chronic Obstructive Lung Disease (GOLD) 2015. 2015.

[34]. Plankeel JF, McMullen B, MacIntyre NR. Exercise outcomes after pulmonary rehabilitation depend on the initial mechanism of exercise limitation among non-oxygen-dependent COPD patients. Chest. 2005; 127(1):110-6. PMID: 15653970. 